\title{
Comparison of conventional and single bottle system for blood cultures
}

\author{
J A WILSON, A J BARRATT, J GRAY, G B STATHAM Department of Microbiology \\ and Public Health Laboratory, Central Pathology Laboratory, Stoke-on-Trent
}

SUMMARY A single bottle blood culture system (Oxoid Signal system) was compared with a conventional two bottle subculturing system. A total of 2016 routine blood samples yielded $186(9 \%)$ clinically important isolates. Of these, $40(21 \%)$ were isolated only in the Oxoid system and $30(17 \%)$ only in the conventional system. One hundred and sixteen (62\%) were isolated from both systems. Volume of blood was not significantly associated with the rate of detection but was significantly associated with the speed of detection. A continuation of the study with a Signal bottle and single conventional bottle confirmed initial results of the increased isolation rate using two systems. The Oxoid single bottle blood culture system was at least comparable with a conventional system in terms of rate of detection of organisms and was superior in terms of speed of detection.

For many years microbiologists have searched for ways to improve the early recognition of microbial growth in blood cultures. Systems have been designed to achieve this using a biphasic method (Septi-Check, Roche), by measurement of carbon dioxide in the head space using radioactive and non-radioactive means (Bactec, Becton-Dickinson), and by measurement of impedance changes (Malthus). Such systems have some advantages over conventional methods and many laboratories now use one of the newer systems. A single bottle blood culture system which uses a defined medium capable of supporting the growth of aerobic and anaerobic organisms has been developed using a Signal system (Oxoid Ltd). Growth generates gas, which forces culture fluid up into an indicator tube. The principle and a comparative trial of the prototype bottle have been previously described. ${ }^{12}$

This study compared the Signal system with a conventional two bottle system used in a routine hospital laboratory. The results of the Signal system were evaluated for the correlation between the speed and rate of detection of organisms and the volume of blood inoculated.

Accepted for publication 26 January 1988

\section{Material and methods}

The Signal system comprises a sealed bottle containing $80 \mathrm{ml}$ defined broth medium under vacuum. After the bottle was inoculated and delivered to the laboratory a signal device was attached. This consists of a needle attached to a sterile signal chamber and a locking sleeve. Gas produced by bacterial multiplication increases the pressure in the bottle and forces culture fluid into the signal chamber. A positive signal is defined as the appearance of culture fluid above the level of the locking sleeve. In this study turbidity of the culture fluid, even in the absence of fluid in the signal chamber, was also taken as an indication for subculture.

After arrival at the laboratory and attachment of the signal device the bottles were agitated gently by hand and incubated at $37^{\circ} \mathrm{C}$. Thereafter they were mixed gently twice daily and inspected at least twice daily for seven days.

A Gram stained smear was examined and subcultures performed on all bottles with positive reactions. Culture fluid was subcultured on to two blood agar plates (containing nicotinamide adenine dinucleotide) and a MacConkey agar plate. The MacConkey and one blood agar plate were incubated in carbon dioxide $(6-7 \%)$. The other blood agar plate was incubated anaerobically using an anaerobic jar and gas generat- 
ing kit (Oxoid). All plates were examined after overnight incubation and again after reincubation for a further 24 hours.

The conventional system consisted of two bottles each containing $75 \mathrm{ml}$ of Schaedlers broth medium (Gibco). This formulation was chosen after extensive investigation of many media, undertaken during evaluation of the Malthus microbial growth analyser (J Gray, unpublished observations). Bottles were inspected daily and one was subcultured after 24 hours' incubation at $37^{\circ} \mathrm{C}$. Both bottles were subcultured after 72 hours and inspection was continued daily for seven days after which time the bottles were discarded. Any bottle found to be cloudy on inspection was subcultured and a Gram stained smear examined. Subcultures were performed on the same media and incubated under the same atmospheric conditions used for the subcultures from the Signal system. For the duration of the study, bottles from both systems were subcultured on the seventh day before being discarded.

Blood culture sets consisting of one Oxoid bottle and two conventional bottles were issued to all wards, covering all major medical and surgical specialties and including severely immunosuppressed and neonatal paediatric patients. Clinicians were asked to take a total of $20 \mathrm{ml}$ of blood, $10 \mathrm{ml}$ for the Oxoid bottle and $5 \mathrm{ml}$ for each of the conventional bottles. The Oxoid bottle was weighed before issue and again on receipt, allowing the volume of blood inoculated to be calculated. Inoculated bottles were collected from central collecting points and delivered to the laboratory on a regular basis (without preincubation). Any positive

Table 1 Positive blood cultures yielding clinically important isolates

\begin{tabular}{|c|c|c|c|c|}
\hline Organism & $\begin{array}{l}\text { Both } \\
\text { systems }\end{array}$ & $\begin{array}{l}\text { Signal } \\
\text { system } \\
\text { only }\end{array}$ & $\begin{array}{l}\text { Conventional } \\
\text { system only }\end{array}$ & Total \\
\hline \multicolumn{5}{|l|}{ Gram negative: } \\
\hline Enterobacteriaceae & 34 & 20 & 7 & 61 \\
\hline $\begin{array}{l}\text { Pseudomonas spp } \\
\text { Haemophilus }\end{array}$ & 3 & 3 & 0 & 6 \\
\hline $\begin{array}{l}\text { influenzae } \\
\text { Neisseria }\end{array}$ & 2 & 0 & 2 & 4 \\
\hline meningitidis & 0 & 1 & 0 & 1 \\
\hline Bacteroids spp & 2 & 3 & 1 & 6 \\
\hline \multicolumn{5}{|l|}{$\begin{array}{l}\text { Gram positive: } \\
\text { Staphylococcus }\end{array}$} \\
\hline $\begin{array}{l}\text { aureus } \\
\text { Coagulase negative }\end{array}$ & 27 & 4 & 10 & 41 \\
\hline $\begin{array}{l}\text { staphylococci } \\
\text { Streptococcus }\end{array}$ & 15 & 3 & 3 & 21 \\
\hline pneumoniae & 13 & 3 & 4 & 20 \\
\hline $\begin{array}{l}\text { Sireptococcus spp } \\
\text { Listeria }\end{array}$ & 18 & 3 & 3 & 23 \\
\hline $\begin{array}{l}\text { monocytogenes } \\
\text { Clostridium }\end{array}$ & 1 & 0 & 0 & 1 \\
\hline perfringens & 1 & 0 & 0 & 1 \\
\hline Total & 116 & 40 & 30 & 186 \\
\hline
\end{tabular}

Table 2 Positive blood cultures yielding unimportant isolates

\begin{tabular}{lllll}
\hline & $\begin{array}{l}\text { Both } \\
\text { systems }\end{array}$ & $\begin{array}{l}\text { Signal } \\
\text { system } \\
\text { only }\end{array}$ & $\begin{array}{l}\text { Conventional } \\
\text { system only }\end{array}$ & Total \\
\hline $\begin{array}{l}\text { Coagulase negative } \\
\begin{array}{l}\text { staphylococci } \\
\text { Others }\end{array}\end{array}$ & 6 & 38 & 175 & 219 \\
Total & 22 & 8 & 17 & 47 \\
& 28 & 46 & 192 & 266 \\
\hline
\end{tabular}

cultures were followed up and the case discussed with the clinicians involved to ascertain the clinical importance. Initial results suggested the importance of using more than one bottle and the study continued using an Oxoid bottle and a single conventional bottle.

\section{Results}

A total of 2016 blood cultures from patients with suspected bacteraemia yielded $186(9 \%)$ clinically important isolates (table 1). Of these, 40 isolates $(21 \%)$ were isolated in the Oxoid system and $30(17 \%)$ in the conventional system: $116(62 \%)$ were isolated from both systems. Enterobacteriaceae isolated included Escherichia coli and members of Serratia, Salmonella, Proteus, Klebsiella, Enterobacter and Citrobacter species.

The Oxoid system yielded $74(4 \%)$ unimportant isolates and the conventional system $219(11 \%)$ (table 2). Most were coagulase negative staphylococci, and in the case of the conventional system were mostly isolated on terminal subculture. Other unimportant isolates were mainly Bacillus spp and coryneforms.

During the trial $35(2 \%)$ Oxoid bottles produced a positive signal but were culture negative. In addition, four organisms produced turbidity but failed to give a positive signal. These organisms were a Citrobacter freundii, a JK diphtheroid, and two strains of Haemophilus influenzae. There was no signal or sign of visible growth with Neisseria meningitidis which was detected only on terminal subculture.

\section{EFFECT OF VOLUME OF BLOOD ON RATE OF} DETECTION IN THE OXOID SYSTEM

Table 3 shows the proportion of positive results detected in relation to the volume of blood sample analysed. As the $95 \%$ confidence intervals for the proportion overlap, the volume of blood sample was not related to the proportion of positive isolates found.

\section{EFFECT OF VOLUME OF BLOOD ON SPEED OF} DETECTION IN THE OXOID SYSTEM

Forty six per cent of all clinically important isolates were detected in less than 18 hours, $54 \%$ in less than 24 hours, and $85 \%$ in less than 48 hours. The only group of organisms with sufficient numbers for statistical analysis were the Enterobacteriaceae (table 4). Statis- 
Table 3 Effect of volume of blood on proportion detected (Oxoid system)

\begin{tabular}{ccc}
\hline Volume $(\mathrm{ml})$ & Total No/No positive & Percentage $( \pm 95 \% \mathrm{CI})$ \\
\hline$<1$ & $122 / 4$ & $3 \cdot 3(3 \cdot 1)$ \\
1 & $84 / 5$ & $6(5 \cdot 0)$ \\
2 & $91 / 4$ & $4 \cdot 4(4 \cdot 2)$ \\
3 & $118 / 16$ & $13 \cdot 6(6 \cdot 1)$ \\
4 & $138 / 12$ & $8 \cdot 7(4 \cdot 7)$ \\
5 & $165 / 19$ & $11 \cdot 5(4 \cdot 9)$ \\
6 & $136 / 10$ & $7 \cdot 4(4 \cdot 4)$ \\
7 & $147 / 8$ & $5 \cdot 4(3 \cdot 7)$ \\
8 & $194 / 14$ & $7 \cdot 2(3 \cdot 6)$ \\
9 & $266 / 17$ & $6 \cdot 4(2 \cdot 9)$ \\
10 & $335 / 23$ & $6 \cdot 9(2 \cdot 7)$ \\
11 & $140 / 18$ & $12 \cdot 9(5 \cdot 5)$ \\
$>11$ & $80 / 6$ & $7 \cdot 5(5 \cdot 8)$ \\
\hline
\end{tabular}

tical analysis of these figures showed that a volume greater than $5 \mathrm{ml}$ gave a significantly quicker speed of detection. (Mann Whitney U-test, $z=1.91, p>0.05$ ).

\section{RESULTS OF OXOID BOTTLE AND ONE \\ CONVENTIONAL BOTTLE}

The total number of specimens from patients with suspected bacteraemias was 1592 , with $148(9 \%)$ of them clinically important. Of these isolates, $27(18 \%)$ were from the conventional bottle only and $28(19 \%)$ from the Oxoid bottle (table 5). Multiple isolates are listed in table 6 . There were no turbid bottles which failed to produce a signal in this part of the study.

\section{Discussion}

The results of the study were encouraging and indicated that the Signal system was at least as good as the conventional system in the rate of detection of organisms. It was also much less affected by contamination with coagulase negative staphylococci than was the conventional subculturing system which reflects the frequency of entering bottles for subculturing. The range of organisms detected was comparable in both systems. A true comparison of speed of detection in both systems was impossible, but the Signal system can be screened visually at any time and the number of positive cultures detected in less than 18 hours approached $50 \%$. Some isolates of Enterobacteriaceae gave positive results in four to six hours. The number of positive cultures detected in less than 18 hours using a conventional system would normally be very small.

The volume of blood inoculated has been shown to
Table 5 Positive blood cultures yielding clinically important isolates (Oxoid system compared with one conventional bottle)

\begin{tabular}{|c|c|c|c|c|}
\hline Organism & $\begin{array}{l}\text { Both } \\
\text { systems }\end{array}$ & $\begin{array}{l}\text { Signal } \\
\text { system } \\
\text { only }\end{array}$ & $\begin{array}{l}\text { Conventional } \\
\text { system only }\end{array}$ & Total \\
\hline \multicolumn{5}{|l|}{ Gram negative: } \\
\hline Enterobacteriaceae & 42 & 15 & 9 & 66 \\
\hline Pseudomonas spp & 4 & 3 & 1 & 8 \\
\hline Acinetobacter spp & 0 & 0 & 1 & 1 \\
\hline Aeromonas & & & & \\
\hline hydrophila & 1 & 0 & 0 & 1 \\
\hline $\begin{array}{c}\text { Haemophilus } \\
\text { influenzae }\end{array}$ & 2 & 1 & 1 & 4 \\
\hline Neisseria & & & & \\
\hline meningitidis & 0 & 0 & 1 & 1 \\
\hline Bacteroides spp & 1 & 1 & 1 & 3 \\
\hline Fusobacteria & 1 & 0 & 0 & 1 \\
\hline \multicolumn{5}{|l|}{ Gram positive: } \\
\hline aureus & 10 & 4 & 4 & 18 \\
\hline Coagulase negative & & & & \\
\hline staphylococci & 11 & 1 & 2 & 14 \\
\hline $\begin{array}{l}\text { Streptococcus } \\
\text { pneumoniae }\end{array}$ & 1 & 1 & 0 & 2 \\
\hline $\begin{array}{l}\text { Sireptococcus spp } \\
\text { Listeria }\end{array}$ & 15 & 1 & 7 & 23 \\
\hline monocytogenes & 0 & 1 & 0 & 1 \\
\hline Clostridium spp & 2 & 0 & 0 & 2 \\
\hline Peptococcus spp & 1 & 0 & 0 & 1 \\
\hline Yeasts & 2 & 0 & 0 & 2 \\
\hline Total & 93 & 28 & 27 & 148 \\
\hline
\end{tabular}

be an important factor in detecting organisms in blood cultures. ${ }^{3}$ One study showed this to be limited to Gram negative bacilli for unexplained reasons. ${ }^{4}$ Statistical analysis of our results failed to confirm these findings, but the number of blood cultures in our study was lower and there were more variables compared with other studies. Factors such as the formulation of medium used may have made the volume of blood less critical, or the clinical threshold for taking blood could have varied.

The use of more than one bottle increases the isolation rate, with both systems detecting positive cultures independently. This is not related to specific genera or species of bacteria. It may be partly explained by the volume of blood inoculated but will also reflect the complex interaction between volume of blood and dilution of antimicrobial factors giving optimal growth conditions in a particular medium.

The volume of blood inoculated does influence the speed of detection of Enterobacteriaceae. When $5 \mathrm{ml}$ or more of blood was inoculated $62 \%$ were detected in less than 18 hours; only $33 \%$ were detected when less

Table 4 Effect of volume of blood on speed of detection of Enterobacteriaceae (Oxoid system)

\begin{tabular}{llllllllll}
\hline & \multicolumn{2}{l}{ Time (hours) } & & \\
\cline { 2 - 7 } & $<18$ & 24 & 48 & 72 & 96 & 168 & Median & Interquartile range \\
\hline Percentage of total vol $<5 \mathrm{ml}$ & 33 & 42 & 84 & 93 & 99 & 100 & 36 & $18-48$ \\
Percentage positive vol $>5 \mathrm{ml}$ & 62 & 75 & 93 & 97 & 99 & 100 & 18 & $18-24$ & 18 \\
\hline
\end{tabular}


Table 6 Positive blood cultures yielding multiple isolates (Oxoid system compared with one conventional bottle)

\begin{tabular}{|c|c|c|c|}
\hline & $\begin{array}{l}\text { Both } \\
\text { systems }\end{array}$ & $\begin{array}{l}\text { Signal } \\
\text { system } \\
\text { only }\end{array}$ & $\begin{array}{l}\text { Conventional } \\
\text { system only }\end{array}$ \\
\hline $\begin{array}{l}\text { Streptococcus } \\
\text { faecalis/Proteus spp } \\
\text { Streptococcus faecalis/ } \\
\text { Staphylococcus aureus } \\
\text { Fusobacterium/Clostridium } \\
\text { perfringens } \\
\text { Bacteroides fragilis/ } \\
\text { Staphylococcus aureus } \\
\text { Escherichia coli/ } \\
\text { Staphylococcus aureus } \\
\text { Escherichia coli/ } \\
\text { Staphylococcus aureus }\end{array}$ & $\begin{array}{l}\text { Both } \\
\text { Both } \\
\text { Both } \\
\text { Both }\end{array}$ & $\begin{array}{l}\text { Both } \\
\text { Both }\end{array}$ & $\begin{array}{l}\text { Escherichia coli only } \\
\text { Staphylococcus } \\
\text { aureus only }\end{array}$ \\
\hline
\end{tabular}

than $5 \mathrm{ml}$ of blood was inoculated. It is worth noting that despite specific requests for $10 \mathrm{ml}$ of blood for the Oxoid bottle, the volume actually inoculated varied widely, with $72 \%$ of bottles receiving less than $10 \mathrm{ml}$.

Positive signs of growth were not detected with Neisseria meningitidis, although it did grow in the Oxoid medium. This finding is at variance with that of Sawnhey et al $^{2}$ and King et al. ${ }^{1}$ In both their trials, however, they used stock cultures, and there is evidence that Neisseria meningitidis behaved differently from stock cultures on primary isolation (personal communication, DE Post, Oxoid Ltd).

There was also the problem of bottles which gave a positive signal, but from which organisms could not be detected by Gram stain or culture. The possibility that these signals were caused by the presence of mycoplasmas or large numbers of white cells has yet to be confirmed. The manufacturers have made improvements in the quality control procedures used in the production of media. This especially allows better standardisation of osmolality which has a considerable role in signal production (personal communication, DE Post, Oxoid Ltd).

Since these improvements and the introduction of the Signal system into routine use there have been no further problems with signal positive and culture negative specimens. In addition, there have been fewer turbid bottles (two of six) which have failed to produce a signal, which was a concern with the early isolates of Haemophilus influenzae.

It was suggested that the use of an orbital shaker could significantly increase the speed of detection when used in the first 24 hours and could also enhance signal production by Neisseria meningitidis. A trial with such a device is in progress and two out of two recent isolates of Neisseria meningitidis have given positive signals.

The Signal system was simple to use with easy recognition of positive blood cultures, confirming the findings of King et al.' We also agree with their findings that certain organisms had diagnostic features both in the broth and in the reservoir-for example, Pseudomonas spp characteristically formed a scum on the surface of the reservoir fluid.

The system is safe, does not require the use of hazardous materials, and does not require automated equipment. There is a considerable saving in the technical time required to process blood culture specimens compared with conventional routine subculture. We do have reservations about its use as a single bottle system. It failed to detect $15 \%$ of positive results, a similar proportion to the conventional system. It is our present practice to use the Signal system with one conventional bottle as a back up. Routine terminal subculture was carried out for one year but has now been abandoned as no clinically relevant isolate was obtained. The conventional bottle is only subcultured when turbid, or in cases of meningitis or suspected meningococcal septicaemia.

We thank Dr M Collins (medical statistician) for his advice and Mrs $J$ Norton for typing the manuscript.

\section{References}

1 King A, Bone G, Phillips I. Comparison of radiometric and gas capture system for blood cultures. J Clin Pathol 1986;39:661-5.

2 Sawnhey D, Hinder S, Swaine D, Bridson EY. Novel method for detecting microorganisms in blood cultures. J Clin Pathol 1986;39:1259-63.

3 Hall MM, Ustrup DM, Washington II JA. Effect of volume of blood cultured on detection of bacteraemia. J Clin Microbiol 1976;3:643-5.

4 Tenney JH, Barth Reller L, Mirrett S, Wang WLL, Weinstein MP. Controlled evaluation of the volume of blood cultured in detection of bacteraemia and fungaemia. J Clin Microbiol 1982;15:558-61.

Requests for reprints to: Dr J A Wilson, Public Health Laboratory, Central Pathology Laboratory, Hartshill Road, Stoke-on-Trent ST4 7PX, England. 